\title{
Tetrahydrobiopterin restores impaired coronary microvascular dysfunction in hypercholesterolaemia
}

\author{
Christophe A Wyss ${ }^{1}$, Pascal Koepfli ${ }^{1}$, Mehdi Namdar ${ }^{1}$, Patrick T Siegrist ${ }^{1}$, Thomas F Luscher², Paolo G Camici³, \\ Philipp A Kaufmann 1 \\ ${ }^{1}$ Nuclear Cardiology, Cardiovascular Center, University Hospital, C NUK 32, Ramistrasse 100, CH 8091 Zurich, Switzerland \\ 2 Division of Cardiology, Cardiovascular Center, University Hospital, Ramistrasse 100, CH 8091 Zurich, Switzerland \\ ${ }^{3}$ MRC Clinical Sciences Centre, Faculty of Medicine, Imperial College of Science, Technology and Medicine, Hammersmith Hospital, \\ London, UK
}

Published online: 22 January 2005

(C) Springer-Verlag 2005

Eur J Nucl Med Mol Imaging (2005) 32:372

DOI $10.1007 / \mathrm{s} 00259-004-1759-7$

\section{Eur J Nucl Med Mol Imaging (2005) 32:84-91}

The affiliation given for the corresponding author P. Kaufmann was incorrect. His correct address is given here:

The online version of the original can be found at http://dx.doi.org/10.1007/s00259-004-1621-y

Philipp A Kaufmann $(\bowtie)$

MRC Clinical Sciences Centre, Faculty of Medicine, Imperial College of Science, Technology and Medicine, Hammersmith Hospital, London, UK

e-mail: pak@usz.ch

Tel.: +41-1-2553555, Fax: +41-1-2554414
Nuclear Cardiology, Cardiovascular Center, University Hospital, Zurich, Switzerland

e-mail:pak@usz.ch

Tel. +41-1-255 3555 (direct 4196)

Fax. $+41-1-2554414$

Further, Dr. Kaufmann received two grants, not one, from the Swiss National Sciences Foundation. The correct acknowledgement is given here:

Acknowledgements. The study was supported by a grant from the Swiss National Sciences Foundation (SNSFProfessorship grant No. PPOOA-68835 and No. 31-68386 to PAK) and the EMDO Stiftung Zurich and the Radiumfonds Zurich. We are grateful to Thomas Berthold, head radiographer, for excellent technical assistance. 